\title{
La bona mort dels reis d'Aragó segons Ramon Muntaner Xavier Renedo
}

A Josep Miquel Sobré, que va morir l'1 de gener de l'any en què se celebraven els 750 anys del naixement de Ramon Muntaner.

En el món on vivim qualsevol menudalla de la vida quotidiana — prendre un gelat, banyar-se al mar o a la piscina, una conversa enmig del carrer - es pot fer pública a través de la xarxa en qüestió de segons. Com a mínim hi ha, però, un fet que, en principi, és territori prohibit per a les xarxes socials i per als comentaris que s'hi generen. No es tracta, però, d'un fet trivial, d'una menudalla, sinó d'un fet definitiu: la mort. Em sembla molt bé que la mort no es converteixi, ni ara ni mai, en un espectacle a les xarxes socials, però, si començo aquest article amb un comentari d'aquesta mena és perquè a l'Edat Mitjana la mort, sobretot la mort dels reis o de les grans dignitats, no gaudia d'aquest estatus: la mort d'un rei havia de ser pública i exemplar, i havia de seguir, com veurem, una sèrie de pautes en bona mesura fixades per la religió cristiana. D'això se'n deia «fer una bona mort» o, com en deia Ramon Muntaner, una «bona fin», una mort preparada a consciència.

En un passatge de la Danza de la muerte castellana, un poema de finals de l'Edat Mitjana, la Mort diu el següent: «A todos los hago iguales, / a los grandes y menores». Els moralistes i els predicadors medievals es van fer un fart de parlar de la igualtat de tothom —-dels pobres i dels rics, dels reis i dels seus súbdits - davant de la mort, però el que no deien, com tampoc no es diu a la Danza de la muerte castellana, era que la mort d'un rei havia de ser diferent de la dels pobres o la dels seus súbdits, perquè un rei havia de morir donant exemple i servint d'exemple. El contrari de la «bona mort» d'un rei era la mort sobtada bé en el camp de batalla, bé a causa d'un accident, d'un assassinat o de la manera que fos. La mort sobtada impedia preparar-se per ben morir seguint el ritual fixat per la tradició. Per aquesta raó era vista amb recel i sovint era interpretada com un càstig diví que feia suposar que el difunt, en no tenir temps per preparar la seva mort, s'havia acabat condemnant.

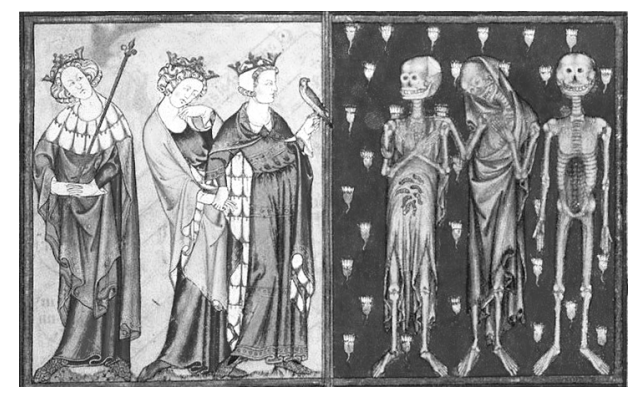

Els tres vius i els tres morts a un psalteri anglonormand, c. 1308-1340 (Londres, British Library, Arundel ms. 83, f. 127v).

Com s'explica a les cròniques de Bernat Desclot i de Ramon Muntaner, el dia de la Mare de Déu d'agost del 1285, en una topada sobtada 
entre tropes catalanes i franceses, que va tenir lloc entre Sant Gregori i Banyoles, sembla que Pere el Gran va estar a punt de morir, i de morir, és clar, de mort sobtada. De fet fins i tot algunes cròniques contemporànies assenyalen que o bé va morir en aquesta topada, o bé en va sortir ferit de mort, encara que trigués un temps a traspassar. Vegem com explica aquest incident el cronista Bernat Desclot:

Entre els altres venc un navarrès qui era amb los cavallers francesos, e vestia un ausberg de ferro, amb son capmall e amb una cervellera en son cap. E viu que el rei d'Aragó los faïa gran mal de ses mans, e acostà's a ell e tramès-li una ascona muntera que portava en la mà, e donà-li tal colp sus en l'arçó de la sella davant, que de l'altra part li'n passà bé un dit. E no plac a Déu que li fes negun mal, car bé sapiats que, si dos dits fos venguda pus alta l'ascona, amb lo rei que no era ben guarnit, de part a part l'haguera tot passat sens tot si. E el rei pres l'ascona amb la mà, e tirà-la tan fort que dos trossos féu del ferro, sí que en l'arçó en romàs ben quatre dits. E d'açò fa testimoni cell qui açò reconta en aquest llibre, que veé la sella del rei e lo ferro que hi era romàs (Cingolani 2010: 404).

'Aleshores va presentar-se un cavaller navarrès que lluitava al costat dels francesos, que vestia un ausberg de ferro, amb un capmall i una cervellera al cap i que, en veure que el rei d'Aragó els feia molt de mal, s'hi va acostar i li va llançar una ascona muntera que duia a la mà. Li va donar un cop tan fort a la part de davant de l'arçó de la sella que l'ascona va sortir per l'altra banda ben bé un dit. I Déu no va voler que fessin mal al rei d'Aragó, perquè heu de saber que si l'ascona hagués anat dos dits més amunt, com que el rei no estava ben guarnit, li hagués travessat, sens dubte, tot el cos. I el rei va agafar l'ascona amb la mà i la va estirar tan fort que va partir el ferro en dos i en l'arçó en van quedar clavats ben bé quatre dits. I d'això dóna testimoni aquell qui reconta aquests fets en aquest llibre, que va veure la sella del rei amb el ferro que hi havia quedat clavat'.2

1 Els Annals de 1285, per exemple, relaten la batalla de la manera següent: «E aprés, lo dia de santa Maria d'Agost, donaren salt franceses al rei d'Aragó prop Gerona, e perdé-hi lo rei d'Aragó dotze cavallers e hòmens molts, e fo-hi nafrat lo rei e quaix [quasi] morí» (citat per S.M. Cingolani 2006: 613). La majoria de cròniques franceses contemporànies diuen el mateix.

2 Si no s'indica el contrari, les traduccions són meves.
Segons Desclot, si l'ascona del cavaller navarrès hagués anat dos dits més amunt, hagués travessat tot el cos del rei, que és molt probable que hagués mort gairebé a l'acte, sense temps, doncs, per preparar-se per ben morir. La providència divina, però, segons el cronista, no va voler que el rei Pere tingués un final com aquest, sens dubte un mal final en tots els sentits, i només va permetre que l'ascona del navarrès travessés l'arçó d'una banda a l'altra. El rei, doncs, en va sortir illès. Moriria al cap de gairebé tres mesos, però al llit i tenint temps, com veurem de seguida, per preparar-se com Déu mana per a la batalla final i sortir-ne victoriós.

Va haver-hi un rei d'Aragó que, molts anys més tard, sí que va morir de mort sobtada prop de Foixà, a l'Empordà, en un accident de caça que va tenir lloc el 19 de maig del 1396. Aquest rei era Joan I, que, a més, era rebesnét de Pere el Gran. La manera com va morir va provocar dubtes molt seriosos sobre la salvació de la seva ànima. Podem llegir el relat de la seva mort en la breu crònica anònima del seu regnat:

E tant volgué usar de la caça que aquest cas li n'esdevenc, ço és, que un dia vinent de Rosselló e essent en la terra d'Empordà fou mogut un llop. E faent-hi soltar los cans, e ell corrent a cavall darrera aquells, los cans hagueren pres aquell. E lo dit rey, cridant, interrogà aquells si era llop o lloba, e no atès a la clusa del dit llop, sobtadament morí no lleixant fill mascle algú, jatsia n'hagués fets haver, però eren-li estats morts (Verrié 1950: 22).

'Tenia tanta passió per la caça que li va passar el següent: un dia, venint del Rosselló i trobant-se ja a l'Empordà, van topar amb un llop. Van deixar anar els gossos de caça i el rei va córrer a cavall al seu darrere. Els gossos van atrapar el llop, però el rei, a crits, va preguntar si era un llop o una lloba, i ja no va tenir temps d'arribar al cau del llop, perquè va morir de sobte sense deixar cap fill mascle viu com a hereu, encara que n'hagués tingut alguns, però havien mort'.

Una mort d'aquesta mena no podia deixar de generar preocupació per la salvació eterna del rei. Semblava ben bé un càstig diví: ho acabava de posar en relleu que Joan I hagués mort sense cap fill mascle que el pogués substituir. (A les planes 
del Llibre dels àngels, escrit quatre anys abans de la mort de Joan I, Eiximenis va recollir uns quants exemples de morts d'aquesta mena, la majoria de vegades protagonitzats per reis i sempre deguts a la justícia divina. Almenys aquesta és la interpretació que en dóna el menoret gironí, que és molt probable, dit sigui de passada, que s'inventés totes aquestes històries.) No és estrany, doncs, que poc després dues persones molt properes al rei escrivissin dues obres on, entre d'altres coses, pretenien esvair aquestes pors i demostrar que el rei no s'havia condemnat, sinó que en realitat estava al purgatori en vies de salvació. Aquestes dues persones són Bernat Metge, secretari del propi Joan I i autor de Lo somni, i el noble rossellonès Ramon de Perellós, autor del Viatge al Purgatori de sant Patrici.

Però deixem de parlar de morts sobtades, reculem cent-onze anys $i$ tornem a dos reis que van morir a pocs dies de distància l'un de l'altre i que van tenir temps, almenys segons el testimoni de Bernat Desclot i del vell Muntaner, de preparar-se a consciència per ben morir: Pere el Gran i Felip III l'Ardit, rei de França.

\section{Com es prepara -i es relata- una «bona mort»}

Ramon Muntaner no va ser present a la mort de Pere el Gran, i encara menys a la del rei de França. Bernat Desclot és molt probable que tampoc no fos present a la mort del rei En Pere. Tot i que no estic d'acord amb la identificació entre Bernat Desclot i Bernat Escrivà, crec, com Stefano M. Cingolani (2006: 666), que no hi va ser present i que es devia basar en documents i en el relat de testimonis que sí que hi van assistir. Muntaner, per la seva banda, coneixia el metge Arnau de Vilanova, que, com es pot llegir en el capítol 143 de la seva Crònica, va assistir Pere el Gran en el seu llit de mort. El metge valencià i el cronista de Peralada van fer un viatge junts poc temps després en una expedició diplomàtica i és possible que, entre d'altres temes, parlessin de la mort del rei.

Joinville, per posar un altre exemple, tampoc no va ser present a la mort de Lluís IX, rei de França, a Tunis, l'any 1270, perquè uns problemes de salut li van impedir acompanyar-lo en la seva croada. Ara bé, com que la «bona fi» d'un rei era un fet molt important en una crònica biogràfica, Joinville no podia no parlar-ne i, per fer-ho, es va basar en un testimoni directe i de fiar de la mort de Lluís IX: Pere, fill del rei i comte d'Alençon. Per això el cita com a font del seu relat de la mort exemplar de Lluís IX:

Et oÿ conter mon seigneur le conte d'Alençon, son filz, que quant il aprochoit de la mort, il appela les sains pour li aidier... (Monfrin 1995: 372).

'He sentit contar al seu fill, el comte d'Alençon, que, quan sentí que s'apropava la mort, invocà la protecció dels sants' (Bagué 1987: 123).

Per tant, encara que ni Desclot ni Muntaner fossin presents en els últims moments de vida de Pere el Gran, podien estar-ne més o menys

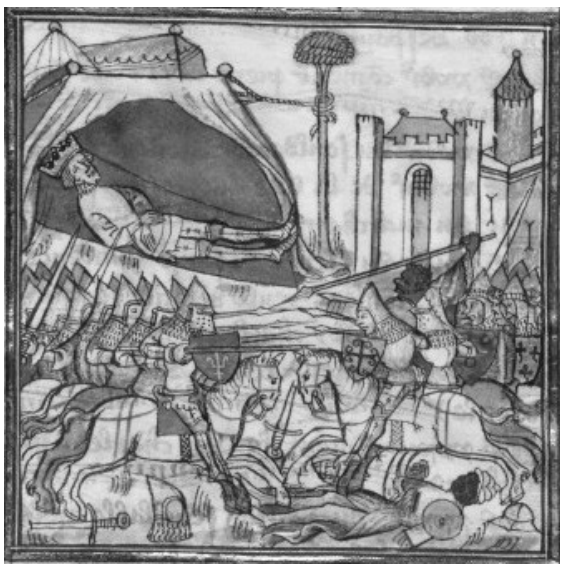

Mort del rei Lluís IX a la batalla de Tunis al 1270 (París, BnF, fr. 2606, f. 319v).

ben informats. I el que no sabien, perquè les seves fonts d'informació no els ho havien explicat, o perquè no ho havien pogut documentar, s'ho devien inventar seguint les pautes de la «bona mort» que un personatge tan exemplar com un rei per força havia d'haver seguit o, si més no, es volia que almenys a les cròniques constés per a la posteritat que així ho havia fet. No era gens difícil omplir els buits suposant que havia passat el que s'estipulava en el protocol de la «bona mort» fixat per la tradició.

És molt probable, en aquest sentit, que el relat que ofereix el vell Muntaner de la mort del rei En Jaume sigui un invent. No crec que Muntaner 
hagués llegit el relat de la seva «bona mort» ni en el Llibre dels fets ni en la Crònica de Desclot. No podem descartar que se n'informés en alguna crònica ara com ara perduda, però no calia prendre tantes precaucions. El «sant rei» En Jaume, com se l'anomena a la Crònica més d'un cop, va ser sempre, segons el testimoni que ofereix el vell Muntaner, un rei exemplar i, per tant, era indiscutible que havia d'haver mort com calia esperar d'un rei de la seva condició. En el fons Jaume I va morir, almenys segons la versió que el propi Muntaner n'ofereix en el capítol 28 de la Crònica, gairebé de la mateixa manera que el seu fill Pere el Gran: es confessa «moltes vegades»; combrega i rep l'extremunció «molt devotament»; convoca fills i néts i els adoctrina i «amb son bon seny i amb sa bona memòria», és a dir amb plena consciència de tot el que fa, mor creuant les mans sobre el pit i resant el Parenostre.

Em sembla que el coneixement que Muntaner podia tenir del Llibre dels fets com a màxim es limitava a la traducció al català dels capítols relatius a la conquesta de Mallorca continguts en el Liber gestorum de fra Pere Marsili (Biosca 2015). És possible que quan Muntaner allludeix a «lo llibre que·s féu de la presó de Mallorcha» (Aguilar 2015b: 41) es refereixi a aquesta traducció, que com a mínim ja està documentada l'any 1331, però que és possible que sigui anterior. Hi ha notícies de la traducció catalana d'aquests capítols, acompanyada del text llatí de Marsili, en una anotació del llibre de fàbrica de la Seu de Mallorca del 1331: «ltem fiu escriure per manament del Senyor Cabiscol vicari I libre en lo qual és escrita la preson de Maylorches en latin e en plan» (Sastre 1994: 66).

Muntaner acaba el relat de la mort del rei En Jaume dient que no té cap dubte de la seva salvació eterna i encomana la seva convicció al lector: «E açò devem cascuns creure» (Aguilar 2015b: 134). El vell Muntaner resumeix la vida del rei amb una frase sentenciosa molt difícil de traduir al «bell catalanesc» dels nostres dies: «bona fo anc nat, e ben perserverà, e en la fin fo me-
Ilor» (Aguilar 2015b: 134), és a dir va tenir, com a rei, un naixement excepcional, anunci de grans meravelles; va saber, a més a més, estar a l'alçada del seu naixement amb conquestes com les de Mallorca, València o Múrcia, que són algunes de les «meravelles» que el seu naixement havia fet preveure que tindrien $\|$ oc, però el millor va ser, sense cap mena de dubte, el seu final, és a dir la seva «bona mort». Muntaner ho diu ben clar: «e en la fin fo mellor». Al final d'aquest article tornarem a parlar de l'excellència de la mort del rei En Jaume segons el relat de Muntaner, i també segons el relat que en va fer el mateix rei en el Llibre dels fets.

\section{Morts anunciades i morts públiques}

Una «bona mort» pot ser una mort anunciada, és a dir prevista amb prou antelació com per tenir temps de seguir fil per randa tot el protocol. El moribund pot tenir, doncs, la intuïció que la seva entrada a l'altre món és imminent. Així comencen les agonies de Lluís IX, segons Joinville; del seu fill Felip III l'Ardit, segons Muntaner, i de Pere el Gran segons Desclot. En el el cas de Lluís $\mathrm{IX}$, Joinville diu el següent:

Apres ce que il fu arrivé a Thunes, devant le chastel de Carthage, une maladie le prist du flux du ventre, et Philippes, son filz aisné, fut mallade de fievre carte avec le flux de ventre que le roy avoit, dont il acoucha au lit, et senti bien que il devoit par tens trespasser de cest siecle a l'autre (Monfrin 1995: 366).

'Un cop (el rei) hagué arribat a Tunis davant del castell de Cartago, li vingué fluix de ventre i el seu fill primogènit Felip fou atacat de febre quartana i de també de la diarrea que tenia el seu pare. El rei s'enllità i de seguida comprengué que ben aviat havia de traspassar d'aquest món' (Bagué 1987: 120).

Respecte a la mort de Felip III només cal fixar-se en les paraules inicials del discurs que, segons Muntaner, adreça als seus fills en el llit de mort. El rei de França té ben clar que morirà abans no es faci de dia i que, per tant, ja no tindrà temps d'abandonar la masia d'En Sord, a Vilanova de la Muga, prop de Peralada.

- Sire Felip, vós sots estat tota hora pus savi en aquests afers que nós, que, si ús haguéssem cregut, ja 
no moriríem nós ací — que serem morts abans que la nuit sia passada - ne tanta bona gent qui en colpa nostra és morta e morrà (Aguilar 2015b: 755).

'- Sire Felip, en tots aquests fets heu estat més savi que Nós. Si us haguéssim fet cas, Nós no moriríem aquí —que podem estar segurs que moriré abans no es faci de dia - ni tanta bona gent que per culpa nostra ha mort i hi morirà'.

I respecte a Pere el Gran, les paraules que, d'acord amb el relat de Desclot, adreça a Jaspert de Botonac, bisbe de València, quan li demana consell per ben morir no poden ser més clares: «E no em consellets així com a rei, mas així com a hom mort, o hom que espera en breu morir, que jo ben sé, e trop en mi mateix, que d'esta malaltia no guarré» (Cingolani 2010: 438) 'No m'aconselleu com a rei, sinó com a home mort o que espera morir ben aviat, que jo sé molt bé, i en tinc plena consciència, que no superaré aquesta malaltia'.

Muntaner no diu en cap moment que Pere el Gran hagués intuït la imminència de la seva mort. No ho diu de forma explícita, però jo diria que això, en el cas d'una «bona mort», sovint es podia donar per suposat i que, per tant, no calia fer-ho explícit en cada relat. En el cas de Muntaner, a més, fins i tot es podria dir que la «cremoreta de febre», el primer símptoma de la malaltia que li acabarà causant la mort, és un senyal diví, perquè un metge de la categoria d'Arnau de Vilanova, un cop feta l'anàlisi de l'orina, no li dóna gaire importància i diu que es tracta només d'un «comoviment de febre», és a dir d'una petita pujada de la temperatura. En aquest cas la ciència s'equivoca, perquè la «cremoreta de febre» té molta més importància que no sembla, i potser fins i tot més transcendència, si és que serveix per posar en alerta el rei, que tan bon punt arriba a Vilafranca del Penedès, la vila on morirà, fa testament —un altre element imprescindible del protocol cristià de la «bona mort», i encara més en un rei, que ha de deixar lligades, i ben lligades, qüestions tan transcendentals com la successió, l'herència i la tria del lloc on reposaran els seus ossos-, fa testament — repeteixo - convoca bisbes i abats, es confessa i es prepara per al final. Segons Muntaner, el rei repassa dues vegades fil per randa el testament, i després el fa llegir dos cops de forma pública «així alt que tuit l'enteseren» (Aguilar 2015b: 779) i, la segona vegada, en demana l'opinió a tots els oients que l'acompanyen en el seu llit de mort, que no són pas pocs, perquè hi ha vuit bisbes, i una munió d'abats, priors, homes d'orde, cavallers, ciutadans i homes de les viles, és a dir representants de tots els estaments del regne. ${ }^{3}$

En la Crònica de Muntaner només hi ha el cas d'un rei que no doni importància als primers símptomes de la malaltia que l'acabarà portant a la tomba. Es tracta del rei Alfons el Liberal, a qui, enmig de festes i espectacles cavallerescos, «venc malaltia d'una naixença, que li féu en la cui$x a$, al raïgal» (Soldevila 2011: 292). Tot i que una «naixença», segons Joan Coromines (1985: 901), és «un tumor, erupció de carn d'origen morbós», el rei Alfons va continuar participant en els jocs cavallerescos «menyspreant», diu Muntaner, «aquella naixença», que li acaba provocant una febre intensa i, a la fi, la mort. El rei Alfons, malgrat l'error inicial, té, però, temps suficient per preparar-se per ben morir, per fer testament amb la màxima cura, per rebre els santíssims sagraments i per exhalar el seu últim sospir creuant els braços sobre la creu que tenia al pit i dient una oració.

Un altre detall del protocol de la «bona mort» d'un rei és que ha de ser una mort pública, davant de les principals autoritats civils i religioses del regne. Ho podem veure en moltes miniatures de les Grandes Chroniques de France que representen la mort de Lluís IX a Tunis. I ho hem vist fa un moment en el relat que ofereix Muntaner de les últimes hores de Pere el Gran. En un altre passatge del mateix capítol Muntaner ho torna a recordar indicant que el rei va combregar «devotament, e amb gran contricció e devoció e en presència de tothom, mentre en la cambra ne pogren caber» (Aguilar 2015b: 775). I em sembla que podem trobar una altra manifestació, o potser una variant, d'aquest detall en una escena que és, sens dubte, un invent de Muntaner: l'arribada a València d'un Jaume I ja moribund després d'ha-

3 Alfons el Liberal mostra la mateixa meticulositat en la preparació del seu testament, perquè, segons Muntaner, «una vegada e dues lo féu llegir e examinar» (Soldevila 2011: 292). 
ver assistit com a mer espectador a la victòria de l'infant Pere sobre els musulmans rebels. ${ }^{4}$ Quan entra a València per morir es troba que «tota la ciutat era eixida a carrera» (Aguilar 2015b: 133). Tot el poble assisteix a l'última entrada del rei a la ciutat i també participa, doncs, de la seva mort.

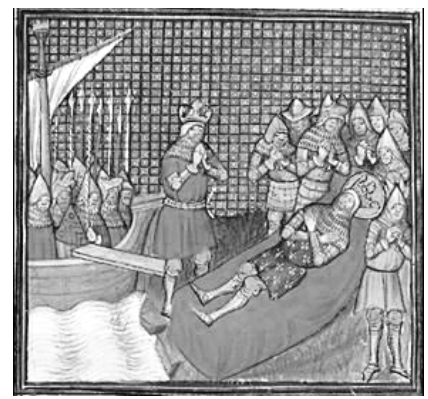

Mort de Lluís IX a Tunis en un manuscrit de les Grandes Chroniques de France, s. XIv (Chantilly, Musée Condé).

\section{La "bona fin» dels reis i de les reines}

En un bell article sobre la mort dels reis de la Corona d'Aragó i de França al Ilarg dels segles XIIIXIV, Andrea Martignoni assenyala que es tracta d'una «muerte exclusivamente masculina, en torno al rey, nada de mujeres» (2012: 27). Ni tan sols les seves pròpies esposes, almenys en els relats de Muntaner i de Desclot, figuren al costat dels reis en les seves últimes hores. I no tan sols això, sinó que a la Crònica de Muntaner la mort de les reines no té el mateix relleu narratiu que tenen les morts dels reis del casal d'Aragó o fins i tot de Felip III. Només Constança de Sicília i Teresa d'Entença mereixen, sobretot la primera, un xic d'atenció en aquest sentit, però, sense donar-los la mateixa importància que es concedeix a la mort d'un rei.

De la reina Constança, per exemple, es dediquen unes quantes línies als seus últims anys, en què com «la mellor crestiana que en aquell temps sabés hom en el món» (Soldevila 2011: 309) va visitar Roma com a pelegrina, va guanyar

4 Per a les invencions i els referents literaris que hi ha darrere d'aquest episodi, vegeu la suggestiva anàlisi d'Aguilar (2012: 223-234). les indulgències i es va entrevistar amb el papa. Després va tornar a Catalunya, va dedicar-se, segons Muntaner, a les obres de pietat en benefici de l'ànima del seu marit, el rei En Pere, i de la seva pròpia, i va morir «menoreta vestida». Constança, doncs, també va preparar-se per ben morir, i Muntaner es va preocupar de recollir-ho per escrit, però centrant-se més en els seus últims anys de vida que no pas en la seva «bona fi»».

Muntaner també es desfà en elogis de Teresa d'Entença, la primera esposa d'Alfons el Benigne, però, tot i que dóna la data exacta de la seva mort («lo darrer dimarts d'octubre de l'any mil tres-cents vint-e-set»), despatxa en ben poques línies la seva «bona fi»». De fet es limita a dir que va rebre els sants sagraments i que va morir de forma exemplar:

Ella fo combregada, e periolada e moltes vegades confessada, així com aquella qui era molt catòlica e graciosa a Déu e al món, e així la volc Déus en son regne nina e jove (Soldevila 2011: 488).

'I ella va combregar i la van extremunciar i es va confessar moltes vegades, perquè era molt catòlica i agraïda a Déu i al món, i d’aquesta manera la va acceptar Déu al seu regne, nena i joveneta'.

Un relat breu que, tot i la seva concisió, traspua l'emoció i el dolor que la mort de la reina va provocar en Muntaner, que potser la va arribar a conèixer. Tot i així, la mort de Teresa tampoc no rep el mateix tractament que el relat de la mort d'un rei.

Desclot, que, a diferència de Ramon Muntaner, no esmenta en cap moment la presència d'Arnau de Vilanova al costat de Pere el Gran en les seves últimes hores, posa en relleu un altre tret que també ha de caracteritzar la «bona mort» d'un rei: la resignació amb què accepta la malaltia i la santa paciència amb què es pren, i segueix una per una, totes les recomanacions dels metges:

E la malaltia s'enfortí tota vegada de dia e de nit sobre ell durament, mas no us cuidets que s'hi faés res per colpa sua, car anc no veés null hom pus obedient a son metge que ell era, que tot ço que li consellava son metge que degués fer segons medicina ell faïa, e no volia altra cosa (Cingolani 2010: 436). 
'I la malaltia es va anar fent sempre més forta, de dies i de nits, però no us penseu que ell en tingués cap culpa, perquè no podeu haver vist mai ningú tan obedient al seu metge com ell, que feia tot el que li manaven segons l'art de la medicina i no volia fer res més que això'.

La malaltia en aquesta mena d'escenes, i en tota la literatura de caire religiós que hi està relacionada, es presenta sempre, com ha assenyalat Andrea Martignoni (2012: 20), com una prova dramàtica que cal acceptar, comprendre i posar al servei de la salvació de l'ànima, que és el que de debò importa. I això és just el que fa, segons Desclot, Pere II en el seu lit de mort. En aquest sentit la seva actitud és el revers exacte del que en les arts de ben morir es definia com a pecat d'impaciència.

\section{Pau i vida eterna}

Un altre punt del protocol de la «bona mort» d'un rei és posar-se en pau amb el món, és a dir resoldre de la forma més amistosa i pacífica possible, sense marge per a sentiments tan poc cristians com la rancúnia o la revenja, tots els problemes polítics pendents. Tot i que d'entrada pot semblar el contrari, en realitat així actua Pere el Gran a la Crònica de Desclot en encomanar al príncep Alfons que s'ocupi de dirigir la invasió de Mallorca, una operació militar que sembla que es podria interpretar com un càstig per la collaboració de Jaume II, rei de Mallorca, en la croada francesa contra Catalunya. Per evitar aquesta interpretació, Desclot s'afanya a introduir una puntualització:

E tot açò faïa lo rei d'Aragó no gens per mala voluntat que hagués a En Jacme, son frare, car del tot perdonà a ell e a tot hom qui malvolgués, segons que dejús oirets, mas açò faïa per tal que trobàs carrera e via com se pogués adobar e avenir amb l'Església de Roma e amb los altres prínceps seglars, e que son pleit ne fos tota hora millor quan tingués ell, de l'altrui, darrere si (Cingolani 2010: 436).

'I tot això el rei d'Aragó ho feia no pas perquè tingués ganes de fer mal a En Jaume, el seu germà, perquè, com més endavant podreu sentir, l'havia perdonat del tot a ell i a tot hom que li hagués volgut mai mal. En realitat, si ell volia ocupar Mallorca, només ho feia per trobar una manera per reconciliar-se i fer les paus amb l'Església de Roma i amb els altres prínceps seculars del món, i perquè els seus problemes se solucionessin quan tingués el suport dels altres'.

De mala voluntat i d'esperit de revenja contra el seu germà, doncs, res de res. Jaume de Mallorca, segons Desclot, està perdonat i ben perdonat. El que cal és resoldre un problema molt més greu —les relacions de la Corona d'Aragó amb el papat- i la conquesta de Mallorca es presenta com una via - potser una mica complicada, cal reconèixer-ho_ - per forçar la situació i arribar a un pacte beneficiós per a la Corona d'Aragó amb el papa. No es tractava, doncs, d'un càstig o, el que encara seria pitjor, d'una revenja, sinó d'una operació política imprescindible per posar remei a una situació del tot injusta. En el seu llit de mort, el rei està per sobre de sentiments mundans.

Pere el Gran, sempre segons el relat de Bernat Desclot, actua seguint ben bé el mateix patró quan decideix donar la llibertat a tots els presoners capturats al llarg de la guerra contra Carles d'Anjou i Felip III, excepte aquells que, com era el cas de Carles el Coix, príncep de Salern, fossin gatges que es poguessin fer servir per negociar una pau avantatjosa per als 
interessos de la Corona d'Aragó. Segons Desclot, es van alliberar fins a mil cinc-cents presoners. (No hi ha cap referència a aquesta decisió a les planes de la Crònica de Muntaner.)

El rei Pere mostra també, d'acord de nou amb la Crònica de Desclot, aquesta mateixa grandesa d'ànim quan, en assabentar-se que les tropes franceses han abandonat Girona, se n'alegra, però no pas per la derrota de l'enemic, que el rei també ja havia perdonat del tot, sinó per la pau que la retirada de l'exèrcit de Felip III portarà a Catalunya:

E a cap de dos o tres dies que aquestes coses foren fetes, venc-li missatge que els francesos qui eren a Girona se n'eren anats, e que havien desemparada la ciutat [...] E lo rei, com ho sabé, sabé-li fort bo, no per mala voluntat que hagués als francesos, que del tot los havia perdonat, mas per tal que, si ell se moria, que sa terra no romangués en treball ne en guerra (Cingolani 2010: 441).

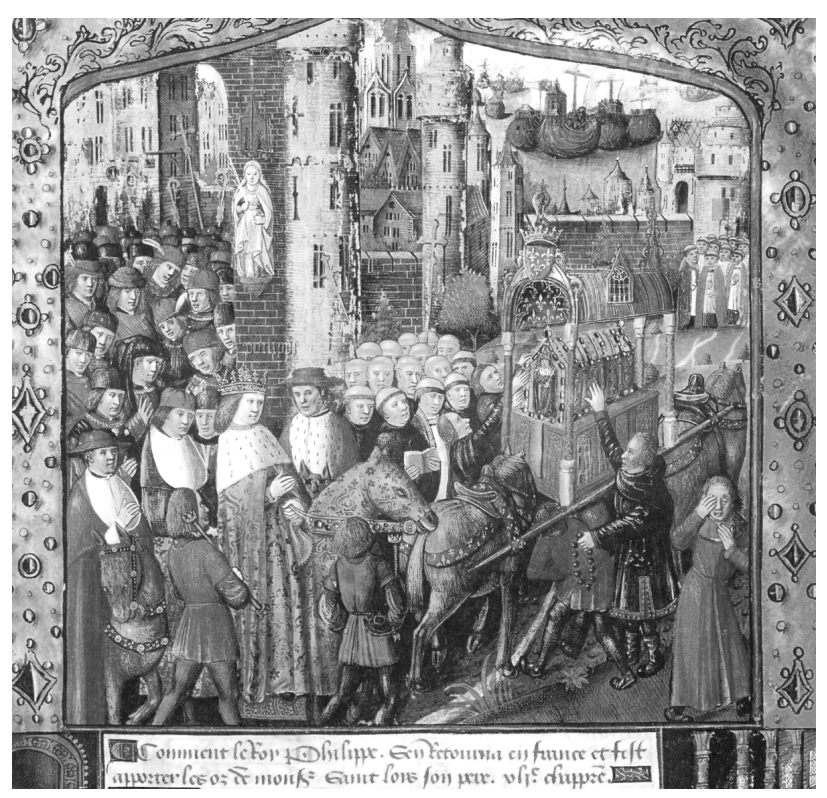

Felip III l'Ardit, rei de França, portant a París el cos del seu pare difunt, sant Lluís. qui ací són entorn, que no els sia fet mal per negun; e els absolvets de tot ço que a Nós fossen tenguts, e que cascun torn a son senyor (Aguilar 2015b: 775).

'Us preguem que procureu que aquesta gent de Castelló, que s'han lliurat a Nós, i dels llogarets del votant, no els faci cap mal ningú, i absoleu-los de tot allò que els obligava envers Nós i que cadascú torni amb el seu senyor'.

La croada ha estat un fracàs, reconeix de forma implícita el rei, però no pot ser que els pecats dels francesos els acabi pagant també la gent de Castelló d'Empúries. Tal com ho explica Muntaner, Felip l'Ardit es preocupa de protegir uns vassalls que li han jurat fidelitat, però també d'impedir que Pere el Gran vulgui venjar-se de la traïció d'una vila empordanesa. I amb el mateix esperit de reconciliació i de concòrdia Felip III recomana al seu fill i hereu que França faci les paus amb la Corona d'Aragó.

Una altra peça imprescindible del protocol

'I al cap de dos o tres dies un missatger li va fer saber que els francesos que assetjaven Girona havien abandonat el setge i s'havien retirat [...] I el rei, quan ho va saber, se'n va alegrar molt, però no pas perquè odiés els francesos, que ell ja havia perdonat del tot, sinó perquè volia que la seva terra estigués tranquilla i en pau després de la seva mort'.

Segons Muntaner, Felip l'Ardit, de fet, actua de forma molt semblant en demanar a l'infant Felip, el seu hereu, que es preocupi de protegir la gent de Castelló d'Empúries i dels voltants, que, com és ben sabut, havien canviat de bàndol i s'havien passat a les files franceses.

Pregam-vos que guardets que aquesta gent de Castelló, qui a Nós s'eren retuts, ne d'aquests altres llogars de la «bona mort» és el comiat dels fills, amb les últimes recomanacions i consells i la benedicció final. El millor exemple en aquest sentit em sembla que el dóna - era inevitable que ho fes, tractant-se d'un rei sant- Lluís IX, que, segons explica Joinville, va lliurar al seu fill Felip, el futur rival de Pere el Gran en la croada del 1285, uns fulls, escrits a mà per ell mateix, amb els seus últims ensenyaments. Jaume l, que és molt probable que no sapigués escriure, no podia aspirar a fer una cosa semblant, tot i que en certa manera el Llibre dels fets es pot interpretar com el seu últim ensenyament als fills.

Tancats els problemes polítics i adreçades les últimes paraules als fills, sobretot als hereus, ja només quedava acabar, si no és que ja s'havia 
començat a fer abans, de fer les paus amb Déu confessant-se per última vegada, combregant sempre «amb gran devoció» i rebent l'extremunció. I, com a punt final de tot el procés, creuar les mans sobre el pit, abraçar la creu i morir amb una oració als llavis. En la Crònica de Muntaner tots els reis del Casal d'Aragó de qui es descriu la mort de forma detallada - Jaume I, Pere II, Alfons II i Jaume II - moren de la mateixa manera: creuen les mans sobre el pit abraçant la creu, se senyen i s'encomanen a Déu amb una oració.

Tots els reis d'Aragó que fan una «bona mort» estan, per descomptat, en vies de salvació —i és evident que no n'hi ha ni un, almenys a la Crònica del de Peralada, que no faci una «bona mort». Potser no calia dir-ho, però un autèntic devot de la religió reial com Muntaner no podia estar-se de subratllar-ho o, quan no ho fa, de glossar algunes de les virtuts que els devien permetre acabar de guanyar-se el cel. Del sant rei En Jaume, el que «bona fo anc nat, e ben perserverà e en la fin fo mellor», potser era de qui menys calia dir-ho, però tot i així Muntaner no va poder contenir-se i va escriure «E així és ma fe que ell sia amb los sants en Paradís. Amén» (Aguilar 2015b: 134). En canvi, potser sí que calia dir-ho d'un rei com Pere II, que tants de problemes va arribar a tenir amb l'Església i que va morir excomunicat:

Llevà los ulls al cel, e l'ànima se partí d'ell així dolçament com si fos un albat, e anà-se'n amb los àngels en paradís. Déus per la sua bonea e mercè vulla que així sia! E així ne devem tuit estar d'opinió, que ell sia ab lo benauirat sant Martí e ab los altres sants en paraís, que anc crestià no fo tan bella fi com ell feú (Aguilar 2015b: 134).

'Va elevar els ulls al cel i l'ànima es va separar d'ell tan dolçament com si fos un albat, i se'n va anar amb els àngels al paradís. Que la bondat i la misericòrdia de Déu vulguin que així sigui! I així tots hem de creure que ell està amb el benaurat sant Martí i amb la resta dels sants en el paradís, perquè mai cap cristià ha fet una fi tan bella com la seva'.

Del rei Alfons el Liberal també es diu que se'n va anar de dret al paradís afegint-hi un detall que dóna compte de la seva exemplaritat:

E sens tot dubte podem estar que amb Déus és en paradís, així com aquell qui se n'anà verge, que jamés no hac paria de fembra, ans era son enteniment que verge vengués a sa muller e que puis així mateix no hagués cura d'altra dona (Soldevila 2011: 293).

'I podem estar ben segurs que és amb Déu al paradís, així com aquell que se n'anà verge, que mai havia estat amb cap dona, ja que la seva intenció era que arribés verge a la seva muller i que, així mateix, no prestés atenció a cap altra dona'.

De l'infant Pere d'Aragó, l'últim fill de Pere el Gran i de Constança, es diu gairebé el mateix: va fer una «bona fi» i s'assegura que era tan «net e pur» que «anc no hac coneguda dona carnalment, mas madona Guillema de Montcada, sa muller» (Soldevila 2011: 315). Del rei Sanç I de Mallorca ni tan sols es diu que fes una «bona fi», però això també es dóna per suposat, perquè, després de dir que va ser un rei honest i just, Muntaner rebla el clau amb una de les seves més grans hipèrboles: «pot hom dir bé d'ell ço que seria fort cosa de dir de negun altre, que per negun temps en si no hac pecat mortal, e açò és vera veritat» (Soldevila 2011: 469). La mort de Jaume II, l'última mort d'un rei que es narra a la Crònica, és també modèlica, però en aquest cas tampoc no es diu res de forma explícita del seu destí ultraterrenal, però calia dir-ho després d'escriure, en una frase molt semblant a la que havia dedicat a Jaume I: «ell hac bon començament, e bona mitjania e ha feta millor fi» (Soldevila 2011: 491).

Pel que fa a les reines, tot i que, com ja hem vist, Muntaner no s'entreté donant gaire detalls de la seva «bona fi», la confiança en la seva salvació també és absoluta. El relat de la fi de la reina Constança acaba amb aquestes paraules: «e segurament que cascun pot haver sa fe que és ab Déu en glòria» (Soldevila 2011: 488). El de Teresa d'Entença es tanca amb aquesta altra frase: «e així la volc Déus en son regne nina e jove» (Soldevila 2011: 309). L'afirmació, però, més rotunda de santedat i de confiança absoluta en la seva salvació té com a protagonista Esclarmonda de Foix, esposa de Jaume II de Mallorca i mare d'un dels personatges que Muntaner més va apreciar: l'infant Ferran de Mallorca. Muntaner, que no només la va poder conèixer, sinó que la va convertir en protagonista d'un dels episodis més divertits de tota la Crònica, només diu de la seva fi que, 
gràcies a Déu, va morir poc abans d'haver pogut conèixer la notícia de la mort del seu fill i tot seguit afegeix:

E pot hom dir d'ella que és santa en paraís, que en el món no era dona tan devota, ne tan humil ne mellor crestiana. E així ella fo en paraís abans que el dol de son fill no veés (Soldevila 2011: 444).

'I d'ella es pot dir que és santa al paradís, ja que no hi hagut dona al món tan devota, ni tan humil ni millor cristiana. I així ella fou al paradís abans de veure el dol de son fill'.

Com ha posat en relleu Nikolas Jaspert (1997), el Casal d'Aragó va intentar diverses vegades portar un membre de la família reial als altars, però mai se'n va acabar de sortir. Per Ramon Muntaner, en canvi, tots els membres del Casal d'Aragó formaven una autèntica beata stirps i era obvi que mereixien ser canonitzats. En tot cas, el problema per Muntaner hagués estat haver de triar-ne un que no s'ho hagués merescut. En la seva Crònica, la santedat dels reis i de les reines del Casal d'Aragó per una banda i, per l'altra, la seva exaltació messiànica, tan ben analitzada per Martí Aurell (1997) i, més recentment, per Josep Antoni Aguilar (2015a: 32-33 i 69-99), són dues cares de la mateixa moneda.

\section{L’alegria de la «bona mort»»}

Un últim detall abans de posar el punt final a aquest article: tot el procés de la «bona mort» s'ha de fer, des del principi fins al final, amb el cap ben clar, amb plena consciència de tots els actes, i fins i tot amb alegria. El millor exemple d'alegria cristiana per haver pogut fer una «bona fi» el dóna, segons la Crònica del de Peralada, un rei que no era sant segons l'Església, però que per Muntaner ho era tant, o potser fins i tot més, que el mateix sant Lluís: el rei En Jaume. Per aquesta raó va morir, segons podem llegir en el capítol 28 de la Crònica, «ab gran alegre que hac ab si mateix com veé la bona fi que Déus li havia atorgada» (Aguilar 2015b: 133) 'amb una gran alegria, que va poder experimentar quan va veure la bona fi que Déu li havia concedit'. I unes línies més endavant Muntaner torna a repetir que Jaume I va morir «ab gran alegria e ab gran pagament ['satisfacció']» (Aguilar 2015: 133).
De fet, encara que dubto molt que el vell Muntaner hagués pogut arribar mai a llegir sencer el Llibre dels fets, m'atreveixo a dir que podem respirar aquesta «gran alegria» en el pròleg del Llibre dels fets. No sé com s'ho va fer el vell cronista de Peralada, sense haver-lo pogut llegir sencer, per intuir l'alegria que traspua en el pròleg de Jaume I. Potser, però, l'únic que va fer Muntaner és donar forma narrativa als ingredients fonamentals del ceremonial de la «bona mort» vigents a finals de l'Edat Mitjana, i afegir a la seva recreació de la mort d'un rei sant un element tan important com l'alegria.

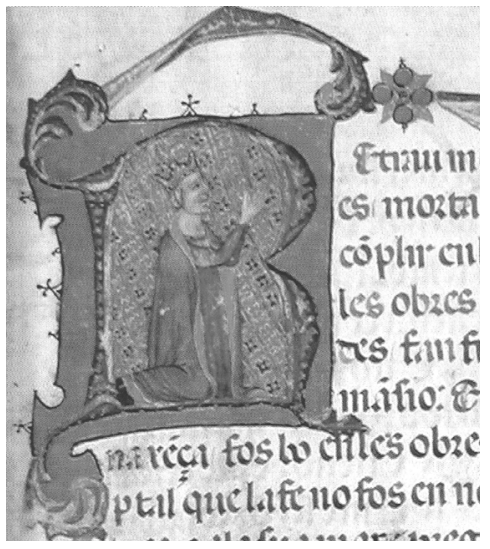

El rei En Jaume pregant poc abans de morir. Caplletra del pròleg del Llibre dels feits del còdex de Poblet de 1343 (Barcelona, Biblioteca Universitària, ms. 1, f. 1r).

Sigui com sigui, en el pròleg del Llibre dels fets el rei En Jaume expressa la seva joia per haver pogut preparar a consciència la seva pròpia «bona mort». Les frases que componen el pròleg les va dir pocs dies abans de morir, potser fins i tot el mateix dia de la seva mort, o ben poc abans. (Recordem, tocant a aquesta qüestió, que el Llibre dels fets és un text que té un origen oral, és a dir que va néixer del discurs oral del rei, no pas, com sovint s'ha dit i de fet encara es diu, d'un dictat.) 5 Per posar-ho en relleu només citaré unes poques frases del pròleg on em sembla que

5 Stefano Asperti i Josep Maria Pujol van fer, a finals del segle passat, contribucions fonamentals sobre aquest tema tan important. A propòsit de tot plegat cfr. l'estat de la qüestió traçat per X. Renedo (2013). 
aquesta alegria cristiana s'expressa d'una forma que no pot ser més nítida ni més diàfana:

E membra'ns bé una paraula que ens retrau la Santa Escriptura, que diu Omnis laus in fine canitur, que vol dir aitant: que la mellor cosa que l'hom pot haver si és a la darreria dels seus anys (E la mercè del Senyor de glòria ha feit a Nós en aquesta semblança perquè es comple la paraula de sant Jaume, que a la darreria de nostres anys volc complir que l'obra s'acordàs amb la fe). ${ }^{6}$

Josep Maria Pujol (2003: 153) va demostrar que el versicle llatí que cita el rei En Jaume de memòria no era de les Sagrades Escriptures, sinó un proverbi llatí medieval, que va ser traduït a diverses llengües, entre elles el català: «a la fi es canta la glòria»». L'error, però, de la cita no té la més mínima importància. L'estil de tot el passatge tampoc no és massa elevat, però el que importa de debò és l'alegria que expressa a través d'aquestes paraules un rei que està a punt de fer una bona mort, fins al punt que poc abans de morir -i potser poc abans, o poc després, de dir, no pas dictar, el pròleg del Llibre dels fetsdesprés de renunciar a la corona en benefici dels seus fills, ingressa en l'orde del Cister i mor com a monjo. Per això Jaume I va poder dir, ple d'alegria cristiana, en el pròleg del Llibre dels fets, «Omnis laus in fine canitur». Per això Muntaner va poder resumir la seva vida, i la seva «bona fi», amb la frase següent: «bona fo anc nat, e ben perserverà e en la fin fo mellor». Com deia Petrarca, un «bel morir», és a dir una «bona mort», «tutta una vita honora».

6 Segueixo l'edició i la puntuació que el malaguanyat Josep Maria Pujol (2003: 163) va proposar per aquestes línies. El mateix JM Pujol (2008: 12) va traduir aquest paràgraf en aquestes termes: «l recordem molt bé un passatge de la Santa Escriptura que diu Omnis laus in fine canitur, que equival a dir que la millor cosa que l'home pot aconseguir, l'aconsegueix a la darreria dels seus anys. I la mercè del Senyor de glòria ha obrat respecte a Nós en demostració d'això perquè es compleixi la sentència de Sant Jaume: que a la darreria dels nostres anys volgué que la nostra conducta s'ajustés a la fe».

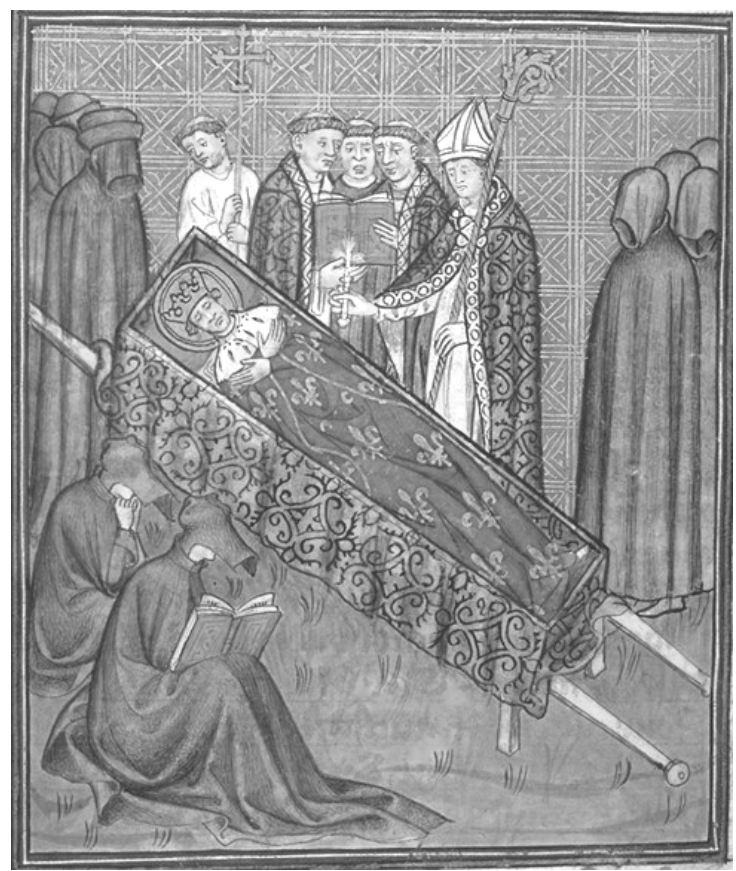

Funeral de Lluís VIII a les Grandes Chroniques de Saint-Denis (Tolosa, Bibliothèque Municipale, ms. 512, f. 267r). 


\section{Bibliografia citada}

AguILAR, Josep Antoni, 2012: «"The Lion in Winter": la figura de Jaume I, del Llibre dels fets a la Crònica de Ramon Muntanerı, ed. Albert Hauf, El Llibre dels fets: una aproximació crítica, València: Acadèmia valenciana de la llengua, 211-237.

AgulLAR, Josep Antoni, 2015a: La Crònica de Ramon Muntaner: edició i estudi (pròleg-capítol 146), vol. I, Barcelona: IEC.

Aguilar, Josep Antoni, 2015b: La Crònica de Ramon Muntaner: edició i estudi (pròleg-capítol 146), vol. II, Barcelona: IEC.

Aurell, Martí, 1997: «Messianisme royal de la Couronne d'Aragon», Annales, Histoire. Sciences sociales, 52/1, 119-157.

Bagué, Enric (trad.), 1987: Joinville, Vida de sant Lluís, rei de França, Barcelona: Publicacions de l'Abadia de Montserrat («Biblioteca Serra d'Or»», 71).

BıoscA, Antoni (ed.), 2015: Petri Marsilii Opera omnia. Liber Gestorum. Epistola ad Abdalla, Turnhout: Brepols Publishers

Cingolani, Stefano M., 2006: Historiografia, propaganda i comunicació al segle XIII: Bernat Desclot i les dues redaccions de la seva Crònica, Barcelona: Institut d'Estudis Catalans.

Cingolani, Stefano M. (ed.), 2010, Bernat Desclot, Llibre del rei En Pere. Barcelona: Barcino («Biblioteca Barcino», 6).

Coromines, Joan, 1985: Diccionari etimològic i complementari de la llengua catalana, vol. V LLNY, Barcelona: Curial Edicions Catalanes-La Caixa.

JASPERT, Nikolas, 1997: «Heresy and Holiness in a Mediterranean Dynasty: the House of Barcelona in the Thirteenth and Fourteenth Centuries»), eds. D.A. Agius i I.R. Netton, Accross the Mediterranean Frontiers: Trade, Politics and Religion, 650-1450, Turnhout: Brepols Publishers, 105-135.

MARTIgnONI, Andrea, 2012: «In hora mortis. Devoción, espiritualidad y actitudes de los reyes ante la muerte», Alia. Revista de Estudios Transversales, I, 16-31.

Monfrin, Jacques (ed.), 1995: Joinville, Vie de saint Louis, París: Garnier («Classiques Garnier»).
Pujol, Josep Maria, 2003: « ¿Cultura eclesiàstica o competència retòrica? El Ilatí, la Bíblia i el rei En Jaume», Estudis Romànics, 21, 147-171.

Pujol, Josep Maria (trad.), 2008: Agnès i Robert Vinas, El llibre dels fets de Jaume el Conqueridor, Mallorca: editorial Moll.

Renedo, Xavier, 2013: «Josep Maria Pujol, el rei En Jaume i el Llibre dels fets», Mot so razo, 12, 19-31.

SASTRE, Jaume, 1994: El primer llibre de fàbrica i sagristia de la Seu de Mallorca 1327 a 1345, Mallorca: Cabildo de la Seu.

SoldeVILA, Ferran (ed.), 2011: Les quatre grans cròniques. III. Crònica de Ramon Muntaner. Revisió filològica de Jordi Bruguera. Revisió històrica de M. Teresa Ferrer i Mallol, Barcelona: IEC.

Verrié, Frederic Pau (ed.), 1950: Crònica del regnat de Joan I, Barcelona. 